\title{
Pelatihan Pengolahan Batang Talas dan Buah Jeruk di Desa Dermojayan Kecamatan Srengat Kabupaten Blitar
}

\author{
Fajar Setyawan $^{1}$, Navita Maharani ${ }^{2}$, Siska Andriani ${ }^{3}$, \\ Ardyana Tri $\mathbf{P}^{4}$, Siti Mariyana ${ }^{5}$ \\ 1,2,3,4,5 Universitas Islam Kadiri \\ email : Fajar_setyawan26@yahoo.com¹, navita.maharani5@gmail.com², siskaandriani2408@gmail.com³, \\ dyanaprawiswara@gmail.com ${ }^{4}$, sitimariyana142020@gmail.com ${ }^{5}$
}

\begin{abstract}
Dermojayan Village, Srengat District, Blitar Regency has abundant plant potential in the form of taro and citrus fruits. This potential can be utilized by the community to increase the added value and selling value of plants. For this reason, it is necessary to conduct training activities on processing taro stems and citrus fruits into products that have economic value and are helpful for the community so that they can increase the income of the Dermojayan village community. Some of the processed products resulting from this activity include lompong chips and orange candy. Post-harvest management and product diversification are still within the home industry's scope, where taro stalks were only used as animal feed in the past. Therefore, the team thought of sharing knowledge and technology with the Dermojayan village community to process lompong chips. Not only taro but there are also citrus fruit plantations covering an area of $800 \mathrm{ru}$ or 11,200 m2 with a total of 800 citrus fruit trees. Sorted citrus fruits, usually only used as orange juice, are processed and made new product innovations by making processed orange candy. It is hoped that the community will be able to open UMKM businesses to lift the economy in Dermojayan village.
\end{abstract}

Keywords: product diversification, taro stems, citrus fruits

\begin{abstract}
Abstrak
Desa Dermojayan Kecamatan Srengat Kabupaten Blitar memiliki potensi tanaman berupa talas dan buah jeruk yang melimpah. Potensi ini dapat dimanfaatkan masyarakat untuk meningkatkan nilai tambah dan nilai jual hasil tanaman tersebut. Untuk itu maka perlu dilakukan kegiatan pelatihan pengolahan batang talas dan buah jeruk menjadi produk-produk yang bermanfaat dan mempunyai nilai ekonomis sehingga dapat meningkatkan pendapatan masyarakat Desa Dermojayan. Beberapa produk olahan yang dihasilkan dari kegiatan ini meliputi kripik lompong dan permen jeruk. Diversifikasi produk buah talas masih terbatas pada rumah tangga, dimana dulu batang talas hanya dimanfaatkan sebagai pakan ternak. Kegiatan bertujuan berbagi ilmu pengetahuan dan teknologi kepada masyarakat desa Dermojayan untuk proses pengolahan kripik lompong. Bukan hanya talas, di sana juga terdapat perkebunan buah jeruk seluas 800 ru atau $11.200 \mathrm{~m} 2$ dengan jumlah 800 pohon buah jeruk. Buah jeruk sortiran yang biasanya hanya dimanfaatkan sebagai es jeruk, diolah dan dibuat inovasi produk baru dengan membuat olahan permen jeruk. Diharapkan masyarakat mampu membuka usaha UMKM sehingga dapat mengangkat perekonomian di desa Dermojayan itu sendiri.
\end{abstract}

Kata Kunci: diversifikasi produk, batang talas, buah jeruk 


\section{Pendahuluan}

Saat ini kompetensi dan pembangunan ekonomi masyarakat pedesaan menjadi perhatian seluruh elemen masyarakat di Indonesia, termasuk perekonomian di wilayah Blitar. Mayoritas masyarakat saat ini cenderung berperilaku semakin konsumtif terhadap sebuah produk yang memiliki nilai manfaat dan ekonomis bagi kehidupan. Salah satunya yaitu diversifikasi produk hasil tanaman yang mempunyai prospek baik finansial atau bermanfaat bagi masyarakat.

Di Desa Dermojayan Kecamatan Srengat Kabupaten Blitar banyak masyarakatnya yang lahan pertaniannya ditanami talas. Akan tetapi mayoritas masyarakat di sana memanfaatkan batang dan daunnya hanya untuk makanan ikan gurami. Sedangkan umbinya diolah untuk dikonsumsi. Talas dapat tumbuh di berbagai daerah baik tumbuh secara liar maupun dibudidayakan. Tanaman talas dapat dijumpai hampir di seluruh Indonesia.

Produksi talas di daerah pedesaan cukup tinggi (Rauf \& Lestari, 2009). Sriyono (2012) menyebutkan bahwa talas banyak ditanam di daerah pedesaan biasanya digunakan sebagai bahan pangan pengganti beras, makanan selingan dan bahkan hanya dibiarkan tumbuh begitu saja. Oleh karena itu perlu adanya pemanfaatan talas menjadi produk olahan baru yang bisa meningkatkan nilai ekonomis dari talas. Tim pengabdian kepada masyarakat mencoba membuat inovasi terbaru untuk memanfaatkan batang talas tersebut untuk dijadikan kripik.

Selain potensi tanaman talas, di desa Dermojayan juga terdapat perkebunan buah jeruk seluas 800 ru atau $11.200 \mathrm{~m} 2$ dengan jumlah 800 pohon buah jeruk milik warga. Buah jeruk sortiran yang biasanya dimanfaatkan masyarakat sebagai es jeruk, oleh tim diolah agar menghasilkan inovasi produk baru dengan membuat diversifikasi buah jeruk menjadi olahan permen jeruk.

Pakpahan (1989) dalam Saliem et al. (2006) menyebutkan bahwa diversifikasi merupakan perluasan dari suatu produk yang diusahakan selama ini ke produk atau industri baru yang sebelumnya tidak diusahakan. Diversifikasi produk bertujuan untuk memperoleh produk baru yang mempunyai nilai tambah lebih, terutama pada aspek ekonomi. Tujuan dari kegiatan ini untuk meningkatkan pendapatan masyarakat desa Dermojayan dan untuk mengetahui produk olahan batang talas dan permen jeruk yang paling efektif untuk menunjang perekonomian warga desa. Tujuan lainnya untuk memberikan pengetahuan bisnis kepada masyarakat UMKM Desa Dermojayan mengenai pembuatan produk baru, packaging, dan cara mema-sarkannya.

\section{Metode dan Pelaksanaan}

Pelatihan ialah sebuah proses yang mencakup serangkaian tindak (upaya) yang dilakukan dengan sengaja dalam bentuk pemberian bantuan kepada tenaga kerja yang dilakukan oleh tenaga profesional. Pelatihan bertujuan untuk meningkatkan kemampuan kerja peserta dalam bidang pekerjaan tertentu guna meningkatkan efektivitas dan produktivitas dalam suatu organisasi (Hamalik, 2001).

Kegiatan pelatihan ini dilaksanakan

di balai desa Dermojayan kecamatan Srengat kabupaten Blitar pada tanggal 18 dan 19 Agustus 2020. Pelatihan ini untuk membekali masyarakat, khususnya ibuibu di desa Dermojayan agar mampu mengolah batang talas dan buah jeruk menjadi olahan produk makanan yang memiliki nilai ekonomis tinggi dan bermanfaat untuk masyarakat.

Kegiatan pelatihan pada hari pertama adalah pengolahan kripik lompong (batang talas). Kegiatan ini berjalan dengan baik dan lancar dan diikuti oleh warga desa Dermojayan khususnya para ibu-ibu yang memiliki tanaman talas. Pada hari kedua, dilakukan kegiatan pelatihan pengolahan 
buah jeruk menjadi permen jeruk. Kegiatan di hari kedua juga berjalan baik dan lancar dengan peserta pelatihan ibuibu warga desa Dermojayan sekitar 15 orang.

\section{Hasil dan Pembahasan Pengolahan Keripik Lompong (Batang Talas)}

Tumbuhan talas mudah didapatkan di seluruh kepulauan Indonesia dan tersebar di daerah dengan ketinggian di atas $1000 \mathrm{mdpl}$. Talas dapat tumbuh secara liar ataupun dibudidayakan. Tingkat produktifitas talas tergantung pada kultivar, umur tanaman dan kondisi lingkungan tempat tumbuh umbi talas (Purwono \& Purnawati, 2007).

Hampir 90\% dari seluruh bagian tumbuhan talas dapat dimanfaatkan, termasuk daun, batang, dan umbi talas. Daun dan batang talas banyak digunakan sebagai sayur yang memiliki kandungan nutrisi yang tinggi. Dalam 100 gram batang talas, terdapat $20 \mathrm{mg}$ fosfor, $60 \mathrm{mg}$ kalsium, $400 \mathrm{mg}$ karbohidrat, $100 \mathrm{mg}$ serat, dan mineral-mineral lain. Karena itu, batang talas banyak dimanfaatkan untuk kesehatan.

Di desa Dermojayan kecamatan Srengat kabupaten Blitar banyak lahan pekarangan yang ditanami tanaman talas, akan tetapi masyarakat belum memanfaatkan potensi talas secara optimal. Batang talas hanya dimanfaatkan untuk makanan ikan gurame. Tim mencoba membuat inovasi terbaru untuk memanfaatkan batang talas tersebut dijadikan kripik. Agar masyarakat juga mampu membuat produk tersebut sendiri di rumah dan membuka usaha UMKM sendiri sehingga mampu meningkatkan pendapatan masyarakat. Batang talas yang semula hanya dibuang atau dijadikan pakan ikan gurame sekarang dapat dimanfaatkan menjadi olahan kripik.

Adapun alat dan bahan yang dibutuhkan dalam pembuatan keripik batang talas (lompong) yaitu : 1) Alat untuk pengolahan kripik meliputi: Kompor, Penggorengan, Peniris, Spatula, Pisau, Baskom/ember, Nampan, Plastik standing pouch kecil, Stiker merk. 2) Bahan untuk pengolahan kripik antara lain: 10 batang talas, 100 gram garam, Bumbu rasa (ayam bawang 100 gram, balado100 gram, hot chilli 100 gram, jagung 100 gram), 5 liter Air, 4 liter minyak goring, 2 $\mathrm{kg}$ tepung terigu.

Proses pembuatan keripik talas (lompong) sebagai berikut: 1) Siapkan batang talas lalu potong tipis secara miring; 2) Cuci batang talas yang sudah dipotong hingga bersih; 3) Rendam potongan batang talas ke dalam air garam selama 3 menit lalu tiriskan; 4) Lumuri batang talas menggunakan tepung terigu; 5) Goreng batang talas dengan api panas sampai berwarna kuning kecoklatan; 6) Angkat lalu tiriskan ke dalam nampan, lalu taburi bubuk rasa sesuai selera; 7) Masukkan ke dalam plastik standing pouch yang sudah diberi stiker merk; 8) Keripik lompong siap disajikan, dinikmati, dipasarkan/dijual.

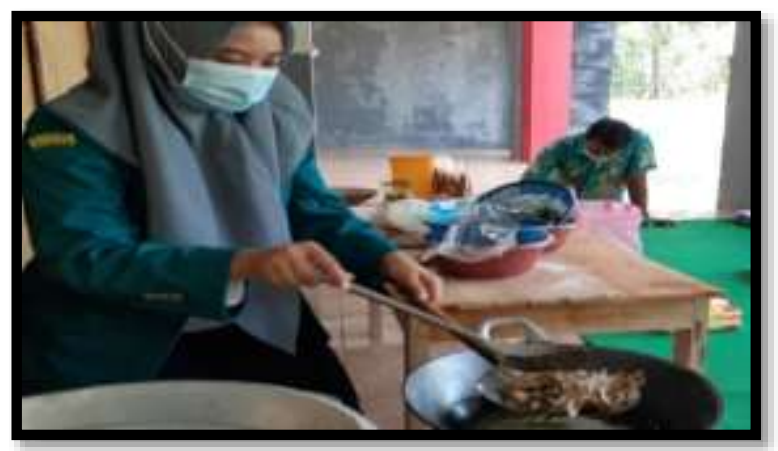

Gambar 1. Pengolahan kripik lompong

\section{Pengolahan Permen Jeruk}

Desa Dermojayan memiliki lahan perkebunan buah jeruk seluas 800 ru atau $11.200 \mathrm{~m} 2$ dengan jumlah 800 pohon jeruk. Buah jeruk mengandung vitamin $\mathrm{C}$ sehinggaa sering dikonsumsi sebagai buah pencuci mulut, diolah menjadi jus, campuran bahan kue, bumbu masakan dan olahan kuliner lainnya. Dengan kreatifitas dan inovasi, buah jeruk juga bisa diolah menjadi permen agar lebih mudah di bawa dan dikonsumsi tanpa mengurangi manfaat 
dan kandungan vitamin yang dikandungnya. Jeruk memiliki kandungan vitamin $\mathrm{C}$ yang cukup tinggi. Dalam 100 gr buah jeruk terdapat vitamin C sebanyak $43 \mathrm{mg}$, sehingga baik untuk mencegah rabun senja dan sariawan (Sunarjono, 2003).

Buah jeruk yang diolah merupakan buah jeruk sortiran yang biasanya dimanfaatkan masyarakat Dermojayan hanya sebagai es jeruk. Disini tim melihat potensi buah jeruk sortiran yang belum dimanfaatkan secara optimal. Oleh karena itu, tim membuat inovasi produk baru dengan membuat diversifikasi buah jeruk menjadi olahan permen jeruk dari buah jeruk sortiran. Setelah mengikuti pelatihan ini masyarakat juga bisa membuat produk tersebut sendiri di rumah dan dapat membuka usaha UMKM sehingga dapat mengangkat perekonomian masyarakat desa Dermojayan itu sendiri.

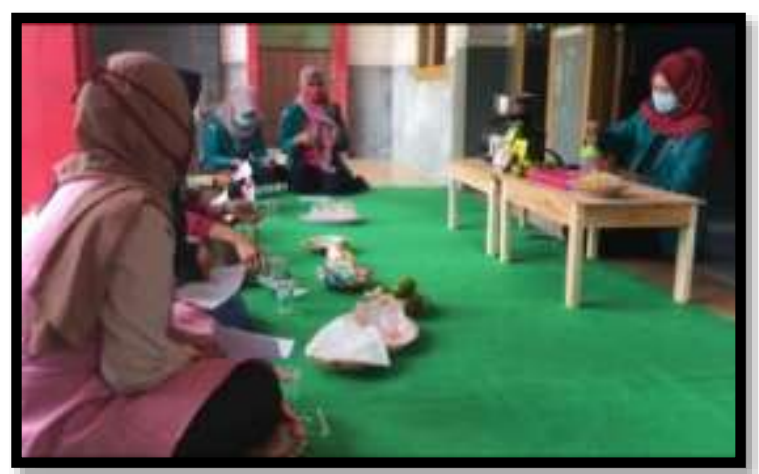

Gambar 2. Proses pembuatan permen jeruk

Adapun alat yang dibutuhkan untuk pengolahan permen ini antara lain: kompor, panci, saringan, gelas ukur, irus, sendok, pisau, nampan, plastik standing pouch kecil. Sedangkan bahan yang dibutuhkan untuk pengolahan permen ini adalah: $1 \mathrm{~kg}$ buah jeruk, $1 \mathrm{~kg}$ gula, 2 bungkus nutrijel, 2 bungkus agar-agar plain, $200 \mathrm{ml}$ air.

Proses pembuatan permen jeruk sebagai berikut: 1) Saring buah jeruk dengan saringan; 2) Campur sari buah jeruk dengan semua bahan yang sudah disiapkan ke dalam panci; 3) Panaskan semua bahan hingga mendidih (sambil di aduk rata); 4) Tuang ke dalam nampan, tunggu dingin, lalu potong persegi; 5) Pisahkan potongan permen, lalu jemur atau diamkan di suhu ruang selama 2 sampai 3 hari; 6) Jika sudah kering, permen siap di pindahkan ke dalam standing pouch untuk dipasarkan (tahan sampai 5 bulan).

\section{Pelatihan dan Pendampingan Pengema- san dan Pemasaran}

Pengemasan dilakukan agar hasil olahan mudah disimpan dan untuk menarik perhatian konsumen. Menurut Kotler (2003) pengemasan adalah sebuah kegiatan merancang dan membuat wadah atau bungkus sebagai suatu produk. Daya tarik kemasan sangat penting guna tertangkapnya stimulus oleh konsumen yang disampaikan oleh produsen. Bila konsumen telah tertarik diharapkan konsumen melakukan pembelian atas produk tersebut

Manajemen yang baik dalam suatu industri akan menentukan keberhasilan dan keberlangsungan usaha. Proses pemasaran yang baik mampu membuat suatu usaha memperoleh nilai ekonomis yang baik pula. Oleh karena itu, tim pelatihan sepakat untuk merancan sistem manajemen keuangan dan pemasaran untuk bisnis yang dibangun.

Untuk pelatihan dan pendampingan manajemen, masyarakat diajari membuat laporan keuangan usaha. Selain itu juga dilakukan pelatihan dan pendampingan dalam pengemasan produk. Dalam kegiatan pelatihan dan pendampingan pemasaran, produk masyarakat dipasarkan secara konvensional dipajang di etalase dan diberi papan merk di depan balai desa Dermojayan agar masyarakat mudah mengetahui keberadaan produk dan mempermudah dalam pembelian atau pemesanan produk.

Selain pemasaran secara konvensional, masyarakat desa juga dikenalkan dan diberi pelatihan untuk kegiatan pemasaran secara daring. Meliputi kegiatan promosi melalui media sosial. Dalam kegiatan ini akan diinventarisir jenis-jenis informasi produk yang akan dimasukan ke 
media sosial, antara lain meliputi nama produk, tampilan produk dan narahubung. Tim pelatihan melakukan perancangan bentuk tampilan untuk masing-masing olahan.

Setelah dilakukan kegiatan tersebut maka akan dipilih penanggungjawab untuk mengelola manajemen dan pemasaran untuk masing-masing usaha. Pemilihan didasarkan pada tingkat pendidikan, kemampuan operasional komputer, tingkat pemahaman terhadap materi yang disampaikan, dan aktifitas dalam kelompok. Secara keseluruhan, kegiatan pelaksanaan pengabdian kepada masyarakat ini terlaksana sesuai tujuan dan target-target yang diharapkan. Dibuktikan dengan masyarakat telah memperoleh pengetahuan, pengalaman, dan keterampilan mengenai olahan batang talas menjadi keripik dan permen jeruk.

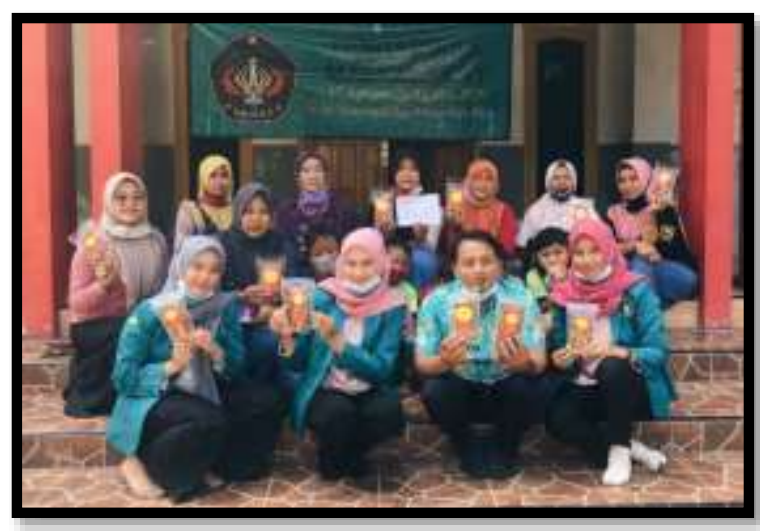

Gambar 3. Foto produk olahan

\section{Simpulan}

\section{Penutup}

Dari kegiatan pengabdian masyarakat mengenai pengolahan batang talas dan buah jeruk di Desa Dermojayan Kecamatan Srengat Kabupaten Blitar dapat ditarik kesimpulan yaitu: 1) Kegiatan pengabdian masyarakat yang dilakukan bersama dengan masyarakat Desa Dermojayan terutama ibu-ibu sangat bermanfaat bagi warga sehingga menghasilkan produk yang berkualitas dan bernilai ekonomi; 2) Kegiatan ini dapat memberikan inovasi baru untuk produk unggulan desa Dermojayan.

\section{Saran}

Mengingat kegiatan pelatihan ini masih sangat terbatas dalam hal waktu pelaksanaan, maka disarankan untuk terus dilakukan pendampingan kepada para peserta oleh tim pengabdian masyarakat, guna memonitoring kegiatan sehingga bisa terus berkelanjutan. Selain itu, berhubung prospek peluang pengembangan usaha ini cukup besar dan potensial maka disarankan kepada pemerintah desa Dermojayan dan pihak-pihak yang terkait untuk memberikan support dan dukungan serta pendampingan untuk optimalisasi potensi desa Dermojayan.

\section{Ucapan Terima Kasih}

Ucapan terima kasih disampaikan kepada Kepala Lembaga Penelitian dan Pengabdian Masyarakat (LPPM) UNISKA Kediri dan Kepala Desa Dermojayan yang telah memberikan ijin dan dukungannya atas terlaksananya kegiatan ini. Selain itu ucapan terimakasih juga disampaikan kepada seluruh masyarakat desa Dermojayan kecamatan Srengat Kabupaten Blitar khususnya para ibu-ibu atas partisipasi dan kerjasamanya sehingga kegiatan ini bisa berjalan dengan baik dan lancar. Ucapan terimakasih juga disampaikan kepada seluruh mahasiswa dan mahasiswi yang terlibat dan ikut bekerjasama dalam kegiatan pelatihan ini. Mulai dari kegiatan perencanaan hingga proses pelaksanaan sehingga semua bisa berjalan dengan baik dan lancar.

\section{Daftar Pustaka}

Hamalik, O. (2001). Pengembangan sumber daya manusia: Manajemen pelatihan ketenagakerjaan pendekatan terpadu. Bumi Aksara.

Kotler, P. (2003). Manajemen Pemasaran. In PT. Indeks (Sebelas).

Pakpahan, A. (1989). Refleksi diversifikasi dalam teori ekonomi. In Refleksi diversifikasi dalam teori ekonomi. Makalah disampaikan pada Kongres dan Konpernas IX Perhepi.

Purwono, L., \& Purnawati. (2007). 
Budidaya Tanaman Pangan. Penerbit Agromedia.

Rauf, A. W., \& Lestari, M. S. (2009). Pemanfaatan komoditas pangan lokal sebagai sumber pangan alternatif di Papua. Jurnal Litbang Pertanian.

Saliem, H. P., Hardono, G. S., Mayrowani, H., Purwantini, T. B., Marisa, Y., \& Hidayat, D. (2006). Diversifikasi Usaha Rumah Tangga dalam Mendukung Ketahanan Pangan dan Penanggulangan Kemiskinan di Indonesia. Forum Penelitian Agro Ekonomi, 24(1), 1-13.

Sriyono. (2012). Pembuatan Keripik Umbi Talas (Colocasia giganteum) dengan Variabel Lama waktu Penggorengan Menggunakan Alat Vacuum Fryer. Universitas Diponegoro.

Sunarjono. (2003). Fisiologi Tanaman Budidaya. UI Press. 